\title{
Additives for Environmentally Adapted Lubricants - Friction and Wear Protection
}

\author{
Anders Pettersson ${ }^{1)}$, Kassfeldt Elisabet ${ }^{1)^{*}}$ and Ichiro Minami ${ }^{2)}$ \\ ${ }^{1)}$ Div. of Machine Elements, Luleå University of Technology \\ SE-97187, Luleå, Sweden \\ ${ }^{2)}$ Dep. of Chemical Engineering, Iwate University \\ 4-3-5 Ueda, Morioka, Iwate 020-8551, Japan \\ *Corresponding author: elisabet.kassfeldt@ltu.se
}

( Manuscript received 27 February 2008; accepted 28 March 2008; published 30 April 2008 )

\begin{abstract}
Five different anti-wear additives, suitable for the formulation of environmentally adapted hydraulic fluids were tested, both commercially available and newly developed. The used base fluid was a high performance saturated complex ester. The formulated fluids' performance was evaluated through the use of an assembled pin \& vee block in a modified Falex wear tester according to wear and frictional behaviour. The combinations of tested materials were steel-steel and bronze-steel tribopairs. The friction, wear scar volume and visual appearance both inside and outside the wear scar were studied. Some of the tested combinations gave unwanted performance, such as high friction, large wear and etching damages, whereas others gave good performance. It was found that the new additives showed promising results for formulation of environmentally adapted lubricants based on saturated complex esters. Further investigations will look closer at the chemical composition of the formed tribofilms with the use of surface sensitive analysis technology.
\end{abstract}

Keywords: tribology, environmentally adapted lubricants, anti wear, additives, boundary lubrication, Falex

\section{Introduction}

The use of environmentally adapted lubricants has become extensive in certain areas, such as mobile hydraulics ${ }^{1)}$. In many areas, the use of environmentally adapted lubricants is driven by legalisation, e.g. the forestry industry in Sweden ${ }^{2}$. One problem with environmentally adapted hydraulic fluids is the relatively poor resistance against aging and degradation compared to traditional mineral based products. A majority of the environmentally adapted hydraulic fluids used today are based on unsaturated ester base fluids ${ }^{3}$. One way to overcome the sensibility for hydrolysis and oxidation is to use saturated base fluids, which introduces new possibilities and new challenges.

The low temperature properties for saturated esters are usually poorer than for unsaturated due to the lack of double bonds that prevent crystallization ${ }^{4}$. One way to overcome this is through the use of complex esters made of one or more ester molecules that are polymerized together with carboxylic di-acids. These structures are free of unsaturations and could give high viscosity index, (VI), excellent stability and good low temperature properties. The combination of fatty acid alcohols and the number of repeating units in the complex ester are endless, making it possible to tailor made base fluids suitable for any application.

Knowledge of suitable additives and formulations for a saturated ester is relatively good, though knowledge of additive response for saturated base fluids is limited ${ }^{5,6)}$.

\section{Tested fluids and materials}

Typical material combinations found in hydraulic applications could be steel-steel and steel-bronze combinations. In this investigation, these materials are tested together with different fluid formulations. Cast iron and cast steels are also common in hydraulic applications, but are not normally such a big problem like the tested materials, and will therefore be left to future investigations.

\subsection{Base fluid and additive properties}

The used base fluid in this investigation is a saturated complex ester; see Table 1. The selected base fluid is suitable for formulating high performance products where environmental aspects are of interest. The base fluid is readily biodegradable, according to OECD 301 $\mathrm{A} / \mathrm{F}$ and some percentage of the base stock is of renewable origin.

The base fluid was additivated with different types of 
Table 1 Base fluid properties

\begin{tabular}{|l|c|}
\hline Viscosity @ $40^{\circ} \mathrm{C}\left[\mathrm{mm}^{2} / \mathrm{s}\right]$ & 46 \\
\hline Viscosity $@ 100^{\circ} \mathrm{C}\left[\mathrm{mm}^{2} / \mathrm{s}\right]$ & 8.1 \\
\hline VI & 150 \\
\hline NPI & $\sim 80$ \\
\hline Pour point $\left[{ }^{\circ} \mathrm{C}\right]$ & $<-50$ \\
\hline Iodine value $[\mathrm{gI} / 100 \mathrm{~g}]$ & $<1$ \\
\hline
\end{tabular}

Table 2 Types of additives.

\begin{tabular}{|l|c|}
\hline Notation & Chemical name \\
\hline PS & Pentasulfie \\
\hline TPPT & Triphenyl phosphorothionate \\
\hline CM & Dithiocarbamate \\
\hline HAP & Hydroxyalkyl phosphate \\
\hline PSHAP & HAP and PS \\
\hline
\end{tabular}

Table 3 Tested materials

\begin{tabular}{|l|c|c|c|}
\hline & Bronze & Steel & Pin \\
\hline Trade name & JM3 & SUJ2 & Falex \\
\hline US standard & 52100 & C90800 & - \\
\hline E [GPa] & 100 & 210 & 210 \\
\hline Hardness & $85 \mathrm{H}_{\mathrm{b}}$ & $60 \mathrm{HRC}$ & $87-91 \mathrm{HRB}$ \\
\hline
\end{tabular}

additives, see Table 2 . The additives were both commercially available and tailor made special additives for saturated esters.

All the used formulations were additivated to 50 $\mathrm{mmol} / \mathrm{l}$ except TPPT, which has $100 \mathrm{mmol} / \mathrm{l}$ concentrations, and PSHAP, which has $50+50 \mathrm{mmol} / 1$ of PS and HAP. Minami et al. describe the preparation of HAP additives in detail ${ }^{7)}$.

\subsection{Tested materials}

The used materials in the tribotests were SUJ2 steel and JM3 bronze; see Table 3 for details.

The used bronze, JM3, is a tin alloyed bronze with approximately $12 \%$ tin. The alloy is extensively used in many different applications. The investigated steel, SUJ2, is a hardened ball bearing steel that corresponds to international standards. The pin is a standard Falex corporation AISI/SAE 3135 steel pin, (HRB 87-91).

\section{Experimental set up}

To obtain data for tribological behaviour and provide tribo-chemically reacted surfaces for surface analysis tribotests have to be run. In this investigation we have chosen to study the tribology in a pure sliding contact.

\subsection{Falex assembled vee block}

The tribotests were run in a modified Falex pin \& vee block machine. The traditional ASTM D-3233 vee blocks were replaced with assembled vee blocks; see Figure 1. The block dimension was $5 \times 5 \times 12.7 \mathrm{~mm}$ and the

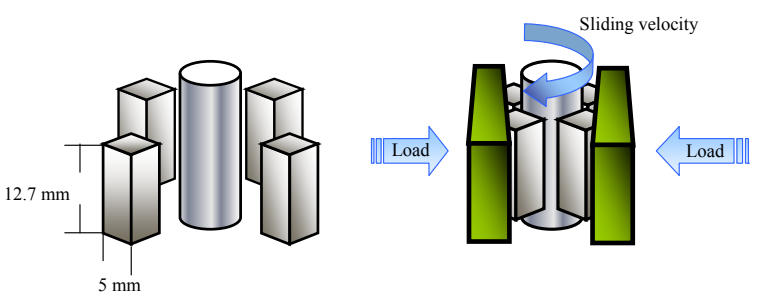

Fig.1 Assembled vee block

Table 4 Running conditions, Falex test

\begin{tabular}{|l|c|c|}
\hline Material & Bronze & Steel \\
\hline Load $[\mathrm{N}]$ & 24.5 & 196.2 \\
\hline Contact pressure [GPa] & 0.10 & 0.35 \\
\hline Test time [min] & 10 & 10 \\
\hline Sliding velocity [m/s] & 0.096 & 0.096 \\
\hline
\end{tabular}

surface finish was approximately $R_{a}=0.02 \mu \mathrm{m}$ to ensure reliable results from the chemical surface analysis. The pin diameter was $6.35 \mathrm{~mm}$.

The advantages with the modified method are the improved accessibility for analysis after the test and the simplified manufacturing of high precision test specimens ${ }^{8)}$. Other benefits are that every test produces four wear scars with a total width of $50.8 \mathrm{~mm}$ with respect to sliding direction. One disadvantage is the risk that damage occurring between one of the blocks and the pin propagates and damages the other blocks at the same position. For test running conditions, see Table 4.

The contact pressure was calculated according to the Hertzian model at the start of the experiment for an unworn contact. All the tests were run at room temperature, (app. $25-28^{\circ} \mathrm{C}$ ) and a relative humidity of $60-85 \%$. The test temperature increased slightly due to friction heating and reached a maximum of app. $50^{\circ} \mathrm{C}$ by the end of the tests.

\subsection{Friction measurements}

The friction coefficient was calculated from the measured normal force and the torque in the Falex machine. A load cell that directly registers the load applied on the blocks by the pneumatic cylinder measured the normal force. A rotational torque sensor attached between the drive unit and the pin holder measured the torque. The load and torque cell were connected to a computerized system that continuously records the values during the test.

\subsection{Wear scar measurements}

The wear scars obtained from the Falex test were analysed in different ways. An optical microscope with an attached digital camera was used to take detailed micrographs of the wear track. The surface profile and topography were measured with a WYKO NT-1100 optical topometer.

The worn off volume was calculated from the wear 


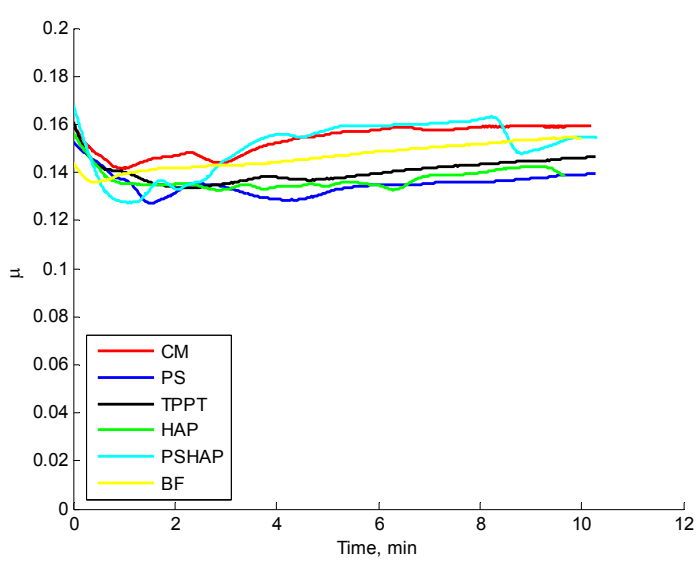

Fig.2 Friction plots for steel

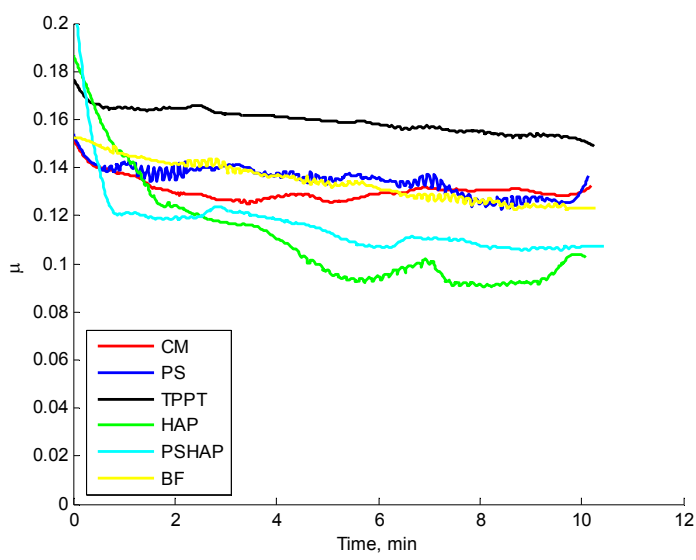

Fig.3 Friction plots for bronze

track 3-D measurements. The presented wear scar volumes are for one block calculated as an average from all four specimens in the same test.

\section{Results and discussion}

The following results are based on a chosen experiment for each additive and material combination. All tests were repeated at least once to ensure good repeatability.

\subsection{Friction}

Load and torque were measured and the friction was calculated and plotted for all steel tests in Figure 2 and for all bronze in Fig. 3.

In Fig. 2, some of the additives (TPPT, HAP and PS) lower the friction according the pure base fluid, (BF). Two of the additives (CM and PSHAP) raise the friction coefficient, though without any big differences. From Fig. 3 for the bronze-steel tribopairs, the friction coefficient shows a larger difference than for steel-steel. The additives PSHAP and HAP show lower friction than the base fluid. PS and CM show a friction coefficient in the same range as the base fluid. The TPPT additive shows a dramatically higher friction than the other additives.

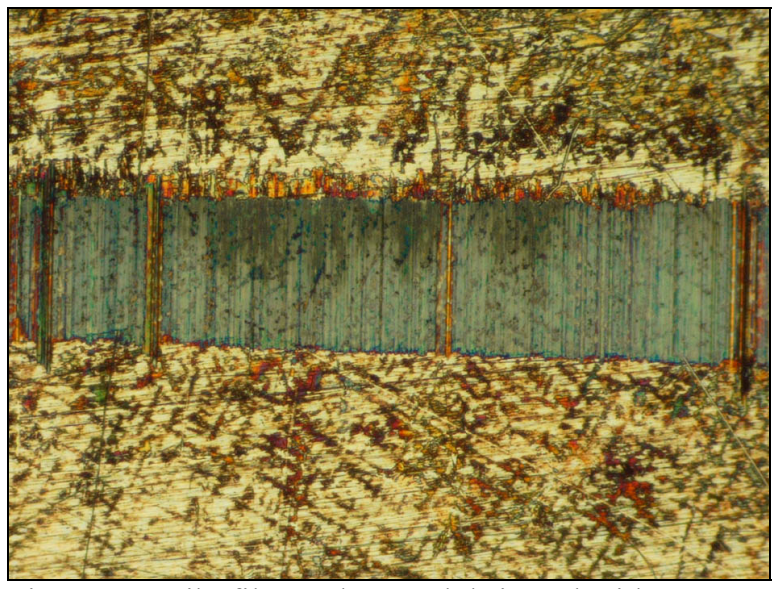

Fig.4 Tribofilm on bronze lubricated with PSHAP

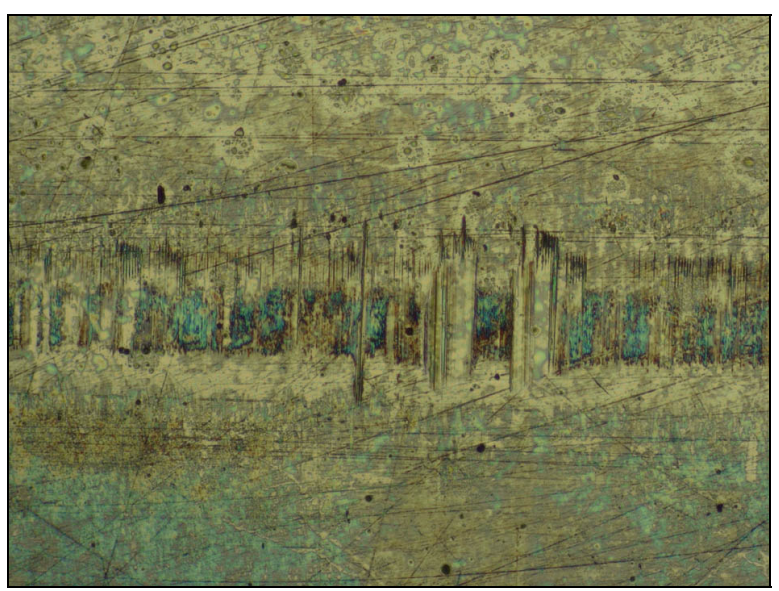

Fig.5 Changes of material outside the wear scar on steel lubricated with HAP

\subsection{Wear scar investigation}

The optical light microscope investigation shows that some of the wears scars have visible tribofilm that show the changes on bronze lubricated with PSHAP; see Fig. 4. The same phenomenon for bronze could also be found for HAP. In the latter case, some transferred material from the blocks on the pin was also seen.

The sizes of the micrographs are $0.8 \times 0.6 \mathrm{~mm}$. Fig 4 and Fig. 5 illustrate the sliding direction from down to upwards.

Some of the visible tribofilms are not continuous in the whole wear scar, as seen in Fig. 5, that show steel lubricated with HAP. In this figure, some effect on the unworn surface outside the wear scar is also seen. This seems to be caused by a chemical reaction between aggressive residual products from the base fluid and additive degradation in the tribocontact. The steel lubricated with the pure base fluid and PSHAP shows similar patterns in the wear scar and on the unworn surface.

There was no visible tribofilm in the wear scar for steel lubricated with PS, but a very strong discoloration could be seen on the unaffected surface.

With the use of a 3-D topometer the following wear scar volumes were obtained; see Table 5. 
The topometer measurements also provide information about surface roughness in the wear scar. This is helpful when trying to determine the wear mechanism, i.e. distinguish between abrasive, chemical or adhesive wear. The bronze lubricated with PS shows an extremely smooth wear scar, as shown in Fig.6 From the corresponding 2-D plot, the sliding direction could be seen; it is downwards in the 3-D plot.

When discolouring outside the wear scar is caused by corrosion, an analysis could be supported by the use of 3-D topometer measurements. This is the case for steel lubricated with HAP, as shown in Fig. 7. The corroded cavities are in the same range as the depth of the wear scar. Corrosive damages are also seen within and outside the wear scar.

Some additives give a discoloration of the unworn surfaces that could probably be handled with AO additives. A summarization of friction behaviour and wear mechanisms for all material combinations is to be found in Table 6 .

Proposed analysis procedure

Conclusions can be drawn differently from the results. The wears scar are analysed visually with a microscope and optical 3-D topometer. The friction can only be analysed, plotted and compared between the different additives.

The wear process can be divided into different cases:

Mild wear and smooth surface: A monolayer of

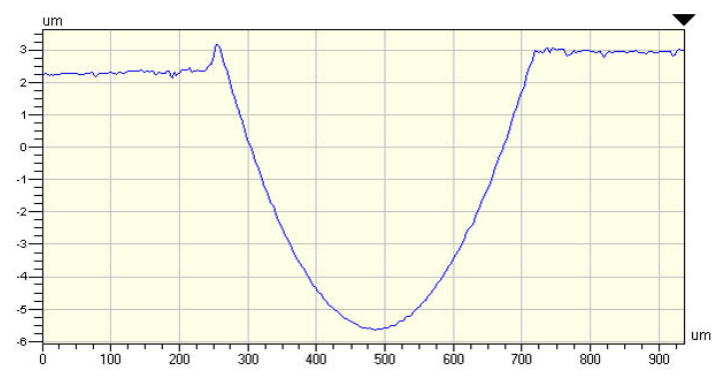

Fig.6 Polished wear scar on Bronze lubricated with PS

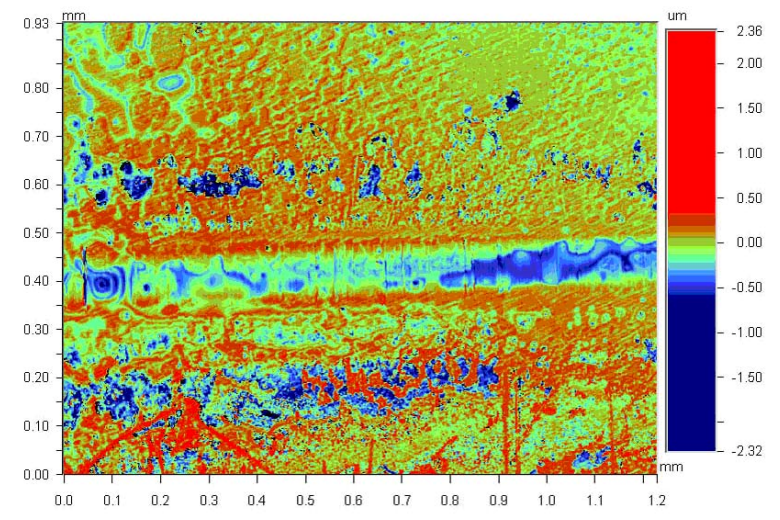

Fig.7 Corrosion damages on steel lubricated with HAP chemireacted tribofilm with good tribological properties is formed. The protective film can handle the load and be rebuilt immediately after breakdown / wear-off. The wear rate and friction are low and the surfaces are smooth.

High wear and smooth surfaces: A weak tribofilm is formed. The built up film cannot handle the load and is broken down, but regenerated continuously at a rapid rate. The wear is severe, but the surfaces are smooth. The friction can be both high and low, though stable depending on the properties of the tribofilm.

High wear and rough surfaces: There is no load carrying the tribofilm. The metal-metal contact is not protected and abrasive, or adhesive wear occurs, or both. The friction coefficient is high, unstable or both.

To classify and understand the wear, a three-step method can be used.

- How do the wear scar and the surrounding area look optically? This is the first step to determine any discolorations.

- How big is the surface roughness inside the wear scar and are there any etching damages outside the scar?

- How big are the wear scar volumes?

The next step is to perform a surface investigation to determine the chemical composition of the surface.

\section{Conclusions}

The additive influence on the friction coefficients and wear in this investigation is bigger for bronze-steel tribopairs than steel-steel tribopairs.

For bronze-steel contact, PS, HAP and TPPT give lower wear than the base fluid. The PS and CM additives give higher wear rate.

All the additives and the base fluid show a low wear rate for steel-steel except the PS additive, which has a much higher wear.

For bronze, the best additives are HAP and PSHAP concerning both wear and friction.

It is interesting to note that some steel samples are affected outside the wear track by the triboreacted products. Examples are HAP and PS, which may be handled by the use of AO additives.

The combined use of active sulphur additives (PS) in bronze contacts should be avoided.

This investigation shows that using new types of more polar additives is a possible way to formulate saturated ester base fluids to lubricants with a high level of performance.

To increase the understanding of tribofilm formation mechanisms, an investigation of the surface with a surface sensitive spectroscopy method is valuable. Future studies will investigate the tribofilms generated by these experiments. 
Table 6 Result remarks

\begin{tabular}{|l|l|l|l|}
\hline Fluid & Friction & Wear scar & Other \\
\hline Base fluid, Steel & Medium friction & $\begin{array}{l}\text { Small wear scar covered } \\
\text { with visible tribofilm }\end{array}$ & $\begin{array}{l}\text { Discoloration outside } \\
\text { wear track }\end{array}$ \\
\hline PS, Steel & Smooth wear track & $\begin{array}{l}\text { Discoloration outside } \\
\text { wear track }\end{array}$ \\
\hline TPPT, Steel & High friction & Small wear scar, & $\begin{array}{l}\text { Deposits outside wear } \\
\text { track, some etching }\end{array}$ \\
\hline CM, Steel & & Low wear & Deposits and etching \\
\hline HAP, Steel & Unstable & $\begin{array}{l}\text { Visible tribofilm with } \\
\text { naked areas }\end{array}$ & Etching damages, \\
\hline PSHAP, Steel & $\begin{array}{l}\text { Visible tribofilm with } \\
\text { naked areas }\end{array}$ & $\begin{array}{l}\text { Discoloration outside } \\
\text { wear track }\end{array}$ \\
\hline Base fluid, Bronze & Decreasing friction & Smooth wear scar & $\begin{array}{l}\text { Low contact pressure in } \\
\text { end of test }\end{array}$ \\
\hline PS, Bronze & Unstable friction & $\begin{array}{l}\text { Very large wear scare, } \\
\text { smooth surface }\end{array}$ & No discoloration \\
\hline TPPT, Bronze & \multicolumn{3}{l}{$\begin{array}{l}\text { Cupper transferred to pin, } \\
\text { no discoloration }\end{array}$} \\
\hline CM, Bronze & Stable friction & Smooth wear track & \\
\hline HAP, Bronze & $\begin{array}{l}\text { Long run in phase, low } \\
\text { friction }\end{array}$ & Small wear scar & Visible tribofilm, \\
\hline PSHAP, Bronze & Low friction &
\end{tabular}

Fully formulated lubricants have numerous additives, but this study is only about single or dual AW/EP additives. Therefore, additional investigations about treat rates, and effects that are synergistic, antagonistic or both should be conducted to successfully formulate commercial lubricants with this new type of additives.

\section{References}

[1] Norrby, T. and Kopp, M., "Environmentally Adapted Lubricants in Swedish Forest Industry - A Critical Review and Case Study," Industrial Lubrication and Tribology, 52, 3, 2000, 116-124.

[2] Norrby, T., "Environmentally Adapted LubricantsWhere are the Opportunities," Industrial Lubrication and Tribology, 55, 6, 2003, 268-274.

[3] Mang, T. and Dresel, W., Lubricants and Lubrication, Wiley-VCH, Weinheim, ISBN: 3-527-29536-4, 2001.

[4] Pettersson, A., "High-Performance Base Fluids for Environmentally Adapted Lubricants," Tribology International, 40, 2007, 638-645.
[5] Weiqiang, Z., Yuping, S., Tianhui, R. and Weimin, L., "The Tribological Behaviour of Some Triazine-Dithiocarbamate Derivatives as Additives in Vegetable Oil," Wear, 256, 2004, 268-274.

[6] Waara, P., Hannu, J., Norrby, T. and Byheden, A., "Additive Influence on Wear and Friction Performance of Environmentally Adapted Lubricants," Tribology International, 34, 2001, 547-556.

[7] Minami, I., Hirao, K., Memita, M. and Mori, S., "Investigation of Anti-Wear Additives for Low Viscous Synthetic Esters: Hydroxyalkyl Phosphonates," Tribology International, 40, 2007, 626-631.

[8] Minami, I., Yamazaki, A., Nanao, H. and Mori, S., "Cylinder and Assembled Four-Block Type Tribo-Test: Novel Method to Study Tribo-Chemistry of Lubricant and Material," Tribology Online, 2, 1, 2007, 40-43. 